\title{
Persistence of orally administered Megasphaera elsdenii and Ruminococcus bromii in the rumen of beef cattle fed a high grain (barley) diet
}

\author{
Athol V. Klieve $\mathrm{A}, \mathrm{B}, \mathrm{C}, \mathrm{D}, \mathrm{E}$, Stuart R. McLennan ${ }^{\mathrm{A}, \mathrm{B}, \mathrm{D}}$ and Diane Ouwerkerk ${ }^{\mathrm{A}, \mathrm{B}}$

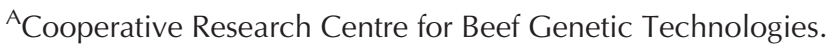 \\ ${ }^{B}$ Department of Employment Economic Development and Innovation, EcoSciences Precinct, PO Box 267, \\ Brisbane, Qld 4001, Australia. \\ ${ }^{\mathrm{C}}$ School of Agriculture and Food Sciences and School of Veterinary Science, University of Queensland, \\ Gatton Campus, Gatton, Qld 4343, Australia. \\ DUniversity of Queensland, Centre for Animal Science, Queensland Alliance for Agriculture and Food Innovation, \\ St Lucia, Qld 4072, Australia. \\ ${ }^{\mathrm{E}}$ Corresponding author. Email: a.klieve@uq.edu.au
}

\begin{abstract}
When cattle are fed grain, acidotic ruminal conditions and decreased efficiency in starch utilisation can result from the rapid production and accumulation of lactic acid in the rumen. The efficacy of drenching cattle with Megasphaera elsdenii and Ruminococcus bromii to improve animal performance was investigated. A feedlot trial was undertaken with 80 Bos indicus crossbred steers (initial liveweight 347.1 (s.d. 31.7) kg) in 10 pens in a randomised complete block design. An empty-pen-buffer was maintained between treated (inoculated) and untreated (control) groups to avoid transfer of inoculant bacteria to the control steers. Inoculated steers were orally drenched with M. elsdenii YE34 and R. bromii YE282, and populations increased rapidly over 3-14 days. The steers were fed for a total of 70 days with commercial, barley-based, feedlot rations. High growth rates $(1.91 \mathrm{~kg}$ per day) were achieved throughout the experiment in both the inoculated and control steers. Intakes averaged $21.3 \mathrm{~g}$ dry matter (DM) per kg liveweight per day. There was probably no acidosis achieved in this trial following challenge (i.e. no change in $\mathrm{pH}$ occurred). There were no differences in any production or carcass measurements between the control and inoculated steers overall. However, the control group acquired dense ruminal populations of M. elsdenii by Day 14, while $R$. bromii populations established at high densities within the first 2 weeks but then declined and were undetectable by Day 50. R. bromii appears to be only transiently dominant, and once its dominance waned, it appeared that Ruminobacter spp. established in the rumen. Ruminobacter spp. became dominant between 14 and 28 days in all the steers examined and persisted through to the end of the study. These Ruminobacter spp. may be of future interest in the development of probiotics for grain-fed cattle.
\end{abstract}

Additional keywords: grain-fed cattle, probiotics.

Received 14 June 2011, accepted 10 January 2012, published online 26 April 2012

\section{Introduction}

In cattle fed grain-based diets, ruminal $\mathrm{pH}$ often falls to low levels (below pH 5) (Dunlop 1972; Nocek 1997; Owens et al. 1998). This decreases the efficiency by which substrate is converted to volatile fatty acids and microbial protein for animal production (Strobel and Russell 1986). The decrease in $\mathrm{pH}$ is often associated with the accumulation of lactic acid, which can lead to acute lactic acidosis (Dawson and Allison 1988). Preventative measures that have been considered both to increase the efficiency of starch digestion and utilisation and prevent the onset of an acidotic condition, include the use of antibiotics (Godfrey et al. 1995; Owens et al. 1998), probiotic bacteria (Kung and Hession 1995; Wiryawan and Brooker 1995; Klieve et al. 2003) and immunisation against Streptococcus bovis (Shu et al. 1999).
In a previous study, Klieve et al. (2003) pursued a probiotic approach whereby lactic acid-utilising and competitive starchutilising bacteria were selected from the rumen of cattle adapted to a high-grain diet and introduced to cattle entering a feedlot. This should augment indigenous populations of these bacteria, thereby preventing acute lactic acidosis, allowing a faster introduction to grain and improving the efficiency of starch utilisation by cattle. Initial work identified a strain of Megasphaera elsdenii (YE34) as a promising lactic acid-utilising bacterium capable of rapidly colonising the rumen of barley-fed cattle (Klieve et al. 2003). In the same study, a strain of Butyrivibrio fibrisolvens (YE44) was selected as a non-lactic acid-producing starch-utiliser but this strain failed to colonise and real-time Taq nuclease assay (TNA) enumeration suggested that all strains of this species of bacterium were rapidly lost from the ecosystem when the cattle were fed a 
barley-based diet. A subsequent study (Klieve et al. 2007) using denaturing gradient gel electrophoresis (DGGE) to identify the dominant bacteria in ruminal contents of these cattle found that the commonly dominant bacterium present at 9-14 days after introduction of the barley diet was Ruminococcus bromii. This species was subsequently isolated using traditional culture-based techniques and its dominance in the grain-fed cattle was confirmed using real-time TNA (Klieve et al. 2007). In some cattle, the population of $R$. bromii reached densities above $10^{10}$ $R$. bromii cell equivalents per $\mathrm{mL}$, or $\sim 10 \%$ of the total bacterial population.

In the current study, we orally drenched cattle on induction into a grain feedlot with M. elsdenii YE34 and R. bromii YE282 to assess their ability to colonise the rumen, persist in the ruminal ecosystem, and to determine whether liveweight gain increased.

\section{Materials and methods}

Pen trial - experimental design

A feedlot growth study over 70 days was undertaken at the Department of Employment, Economic Development and Innovation's Brigalow Research Station, Theodore, Queensland $\left(24^{\circ} 50^{\prime} \mathrm{S}, 149^{\circ} 48^{\prime} \mathrm{E}\right)$. The trial had the ethical approval of Staff Access Animal Ethics Committee (approval number SA 2005/09/49). Animals used were a combined group of high-grade Bos indicus steers, predominantly Droughtmaster and Droughtmaster $\times$ Brahman crossbreds $(\sim 50 \%$ B. indicus $)$ from two properties. The estimated age of both groups was 12 months and initial average liveweight was $347.1 \pm 31.7$ ( \pm s.d.) kg. Eighty steers were divided among 10 pens in a randomised complete block design with five replicates of two treatments (control and inoculated). Steers were allocated to pens by stratified randomisation on the basis of unfasted liveweight, property of origin and for one property group, phenotype description. Within each pen, three steers from the same property of origin and the same liveweight blocks were selected for rumen sampling during the trial. Treatment groups were assigned to pens such that an empty-pen-buffer was maintained between control and inoculated groups to avoid transfer of inoculant bacteria to controls.

\section{Bacteria, culture and storage}

Stock cultures of M. elsdenii YE44 and R. bromii YE282 were grown in a rumen fluid-based medium, with either lactate or maltose as the sole source of energy, respectively (Klieve et al. $2003,2007)$, and stored at $-80^{\circ} \mathrm{C}$ by the method of Teather (1982). Starter cultures ( $5 \mathrm{~mL}$ ) were incubated at $39^{\circ} \mathrm{C}$ overnight. Under anaerobic conditions (Coy laboratory anaerobic chamber, Coy Laboratory Products Inc., Ann Arbor, MI, USA; 95\% $\mathrm{CO}_{2}$, $5 \% \mathrm{H}_{2}$ ), each $5-\mathrm{mL}$ culture was added to a $500-\mathrm{mL}$ serum bottle (Wheaten, Millville, NJ, USA) containing $250 \mathrm{~mL}$ of broth and incubated at $39^{\circ} \mathrm{C}$ overnight. A $250-\mathrm{mL}$ volume of anaerobic rumen fluid-based medium to glycerol $(1: 1$, vol/vol) solution was added anaerobically, the bottle resealed, contents mixed well and stored frozen at $-20^{\circ} \mathrm{C}$ (Klieve et al. 2002). Cultures were thawed, well mixed and three bottles from each bacterial species were subsampled for later enumeration by real-time polymerase chain reaction (PCR) and determination of inoculum dose, before inoculation.

\section{Induction, inoculation and feeding}

Following allocation into treatment groups, all control replicates were moved to pens. Inoculated groups were then inoculated with M. elsdenii YE34 and R. bromii YE282, before being moved to pens. These steers each received $100 \mathrm{~mL}$ [M. elsdenii YE34 at $1.32 \times 10^{9}$ cell equivalents per $\mathrm{mL}$ and $R$. bromii YE282 at $2.89 \times 10^{7}$ cell equivalents per $\mathrm{mL}$ ] of each bacterial species by oral inoculation, using standard drenching equipment.

The steers were fed for a total of 70 days with commercial feedlot diets incorporating starter (Days 1-6), intermediate (Days 7-12) and finishing (Days 13-70) rations (Table 1). The steers were fed once daily around noon, using a 'clean bunk at midday' management system (Lawrence 1998). At all times, the control groups were fed first, then the inoculated groups, to reduce the likelihood of transfer of inoculant bacteria. The same rule was applied to all other management and sampling procedures where close proximity to the steers was expected. Daily feed allocation was determined on the basis of the amount of feed remaining just before feeding but once weekly any residual feed was removed, weighed, subsampled for DM content, and returned to the bunk. Feed that became wet was removed, weighed, subsampled for DM content and discarded. Samples of the ration fed were taken daily, refrigerated $\left(4^{\circ} \mathrm{C}\right)$, bulked weekly, and two subsamples were taken, one for DM determination and the other, which was stored frozen, for chemical analysis. All samples for DM determination were dried at $100^{\circ} \mathrm{C}$ for $24 \mathrm{~h}$. At the end of the experiment, one bulked subsample of the starter and intermediate feeds, and two of the final ration (Weeks 3-6, 7-10) were mixed, dried to constant weight at $60^{\circ} \mathrm{C}$ and ground to pass through a $1-\mathrm{mm}$ screen before analysis.

\section{Sampling and data collection}

The health status of animals was checked using a pen walk each morning and any symptoms of acidosis, e.g. lameness, were recorded.

Table 1. Proportional and chemical compositions of the three rations fed

\begin{tabular}{lccc}
\hline Parameter & $\begin{array}{c}\text { Starter } \\
(1-6 \text { days })\end{array}$ & $\begin{array}{c}\text { Intermediate } \\
(7-12 \text { days })\end{array}$ & $\begin{array}{c}\text { Finisher } \\
(13-70 \text { days })\end{array}$ \\
\hline \multicolumn{4}{c}{ Ration composition $(\mathrm{g} / \mathrm{kg}$ total, as fed $)$} \\
Barley & 500 & 610 & 705 \\
Sorghum silage & 60 & 90 & 90 \\
Wheat straw & 60 & 60 & 20 \\
Lucerne hay & 100 & - & - \\
Cottonseed - high lint & 70 & 80 & 90 \\
Molasses & 150 & 80 & 30 \\
Copra meal & 35 & 35 & - \\
Vegetable oil & - & 10 & 20 \\
Pre-mix & 25 & 35 & 45 \\
& & & \\
& Chemical composition (dry & matter basis $)$ & \\
Organic matter $(\mathrm{g} / \mathrm{kg})$ & 939 & 946 & 951 \\
Crude protein $(\mathrm{g} / \mathrm{kg})$ & 139 & 141 & 144 \\
Fat $(\mathrm{g} / \mathrm{kg})$ & 33 & 48 & 67 \\
Crude fibre $(\mathrm{g} / \mathrm{kg})$ & 111 & 94 & 90 \\
Ca $(\mathrm{g} / \mathrm{kg})$ & 5.9 & 5.7 & 6.0 \\
P $(\mathrm{g} / \mathrm{kg})$ & 2.6 & 2.7 & 3.0 \\
Metabolisable energy $(\mathrm{MJ} / \mathrm{kg})$ & 12.4 & 12.9 & 13.4 \\
\hline
\end{tabular}


The steers were weighed at Days 14, 28, 50 and 70. Rumen sampling of the selected steers (three steers per pen) was carried out on Days 3, 14, 28 and 50. Rumen fluid was collected per os with a stomach tube and vacuum pump, as previously reported (Klieve et al. 1998), for $\mathrm{pH}$ determination and microbial analysis. At all times, the control groups were sampled first and returned to pens before sampling the inoculated groups. Rumen fluid (50-100 mL) was collected, strained through nylon gauze into an open-mouthed jar and the $\mathrm{pH}$ was recorded immediately. From each sample, four 1-mL aliquots were placed in 1.5-mL eppendorf tubes and centrifuged at $12000 \mathrm{~g}$ for $15 \mathrm{~min}$. The supernatant fluid was discarded and remaining pellets frozen on dry ice before transport and storage at $-20^{\circ} \mathrm{C}$. An additional $4 \mathrm{~mL}$ aliquot of rumen fluid was placed into a container with mercuric chloride (to prevent further fermentation) for determination of lactic acid content, as previously reported (Ouwerkerk and Klieve 2001). The samples for lactic acid determination were frozen on dry ice before transport and storage at $-20^{\circ} \mathrm{C}$. Lactic acid concentration was determined as previously reported (Ouwerkerk and Klieve 2001).

\section{DNA extraction, PCR amplification, DGGE and bacterial enumeration}

DNA was extracted from rumen samples by physical disruption using a bead beater as described previously (Whitford et al. 1998). The hypervariable V3 region of the bacterial 16S rRNA gene was amplified from all of the bacteria in each sample using primers 341F-GC (5'-CGC CCG CCG CGC GCG GCG GGC GGG GCG GGG GCA CGG GGG GCC TAC GGG AGGCAGCAG-3') and 534R (5'-ATT ACC GCG GCT GCT GG-3') (Muyzer et al. 1993).

DGGE was used to separate the PCR products to produce a profile from which the diversity of bacteria present in the sample could be estimated (Klieve et al. 2007). The PCR products were loaded onto a DGGE gel with a 30-60\% denaturant range. A reference ladder (Klieve et al. 2007) was also loaded onto the gel to allow comparison within denaturing gradient gels. The gel was then electrophoresed at $100 \mathrm{~V}$ for $18 \mathrm{~h}$ in $0.5 \times$ TAE (Tris-acetic acid-EDTA) buffer, at $60^{\circ} \mathrm{C}$. Following electrophoresis, the gel was silver-stained to visualise the DNA (Kocherginskaya et al. 2005).

Populations of $M$. elsdenii, R. bromii and S. bovis were enumerated using real-time TNAs as previously reported (Ouwerkerk et al. 2002; Klieve et al. 2003, 2007).

\section{Identification of bacterial species from DGGE gels, DNA sequencing and sequence analysis}

The DNA from selected bands was isolated and sequenced to identify the bacterial species represented by that band. The materials and methods involved in this process were identical to those reported in detail by us previously (Klieve et al. 2007). Briefly, a sample of the DNA was obtained by stabbing through the band of interest with a needle (or pipette tip). The $\mathrm{V} 3$ region was re-amplified by PCR and a clone library of the PCR products produced in E. coli cells (TA Cloning Kit, Invitrogen, Carlsbad, CA, USA). Approximately 20 clones for each band were selected, plasmid DNA containing a copy of the original product was extracted from the clones and the V3 region was amplified and run on a DGGE gel alongside the DNA banding profile from the original rumen sample to confirm the clones contained the correct insert, i.e. the V3 PCR product migrated to the same position as the band that the stab was taken from. Five clones containing the correct insert had their V3 region sequenced (Griffith University sequencing facility) and three identical sequences from different clones were deemed sufficient for assigning the sequence to a specific band (Klieve et al. 2007). The sequence was subsequently compared with others in the GenBank database to determine species identity and phylogenetic position (Ouwerkerk and Klieve 2001).

\section{Statistical analysis}

Live animal data (weight, body condition score and hip height) and carcass data (carcass weight, dressing percentage and P8 fat) were analysed by standard ANOVA, with pen as the experimental unit and animal as a sampling term. Further, liveweight growth profiles were examined by repeated-measures analysis using the method of residual maximum likelihood and modelling the variance-covariance matrix.

Average daily pen feed intakes were calculated for selected periods. Feed conversion efficiency over the selected periods was calculated for each pen as the ratio of average DM intake (DMI) and the average liveweight gain over the respective periods. Because feed intakes were collected on a pen basis, average feed intake (DMI) and feed conversion efficiency over the selected feedlot periods were analysed by ANOVA, excluding the sampling term. Weekly DMI profiles were also assessed by repeated-measures analysis using residual maximum likelihood and modelling the variance-covariance matrix.

\section{Results}

\section{Feed intake, liveweight gain and carcass measurements}

There were no statistically significant differences between treatments in relation to liveweight, intake, height, body condition, rumen fluid $\mathrm{pH}$ or carcass measurements (see Table 2). The steers in general ate well throughout the trial and this was reflected in the high rate of liveweight gain. For reasons of interpretation, the trial period has been divided into the first 4 and last 6 weeks. There was little difference in DM intake between treatment groups in the first 4 weeks of the trial (see Table 2). While intakes were marginally higher for the inoculated steers in the last 6 weeks and overall, these differences were not significant. The pattern of intakes (Fig. 1) indicates a trend towards higher intakes by the inoculated steers in the latter part of the trial. However, this coincides with poor performance of one pen in the control group (Pen 7), and one steer in that pen in particular. This steer lost $2 \mathrm{~kg}$ over the last 3 weeks for reasons unknown but not apparently related to acidosis.

High growth rates were achieved throughout the experiment in both groups (Table 2), but particularly in the first 4 weeks. Liveweight changes generally reflect changes in intake and growth rates were slightly higher for inoculated than control steers for the final 6 weeks.

\section{Acidosis - physical symptoms, ruminal $\mathrm{pH}$ and lactic acid concentrations}

There was only one obvious case of laminitis, a control steer at 4 weeks, but this steer subsequently recovered and was not 
Table 2. Feed intake, liveweight gain, body condition and carcass characteristics averaged across steers in the control and inoculated treatments

\begin{tabular}{|c|c|c|}
\hline Parameter & Control & Inoculated \\
\hline \multicolumn{3}{|c|}{ Dry matter intake (kg/day) } \\
\hline Weeks $1-4$ & 7.69 & 7.57 \\
\hline Weeks 5-10 & 9.48 & 9.74 \\
\hline Weeks $1-10$ & 8.76 & 8.87 \\
\hline \multicolumn{3}{|c|}{ Dry matter intake (g/kg LW per day) } \\
\hline Weeks $1-4$ & 20.3 & 20.2 \\
\hline Weeks $5-10$ & 21.3 & 22.0 \\
\hline Weeks $1-10$ & 21.1 & 21.5 \\
\hline Initial liveweight (kg) & 349.8 & 345.3 \\
\hline Final liveweight (kg) & 480.5 & 481.4 \\
\hline \multicolumn{3}{|c|}{ Liveweight change ( $\mathrm{kg} /$ day) } \\
\hline Weeks $1-4$ & 2.11 & 2.08 \\
\hline Weeks 5-10 & 1.71 & 1.85 \\
\hline Weeks $1-10$ & 1.87 & 1.94 \\
\hline Feed conversion ratio $(\mathrm{kg} / \mathrm{kg})-$ Weeks $1-10$ & 4.70 & 4.57 \\
\hline Carcass weight $(\mathrm{kg})$ & 250.0 & 251.0 \\
\hline Dressing percentage & 52.0 & 52.1 \\
\hline P8 fat depth (mm) & 10.0 & 10.3 \\
\hline Body condition score change & 2.19 & 2.36 \\
\hline Final body condition score & 6.8 & 6.8 \\
\hline
\end{tabular}

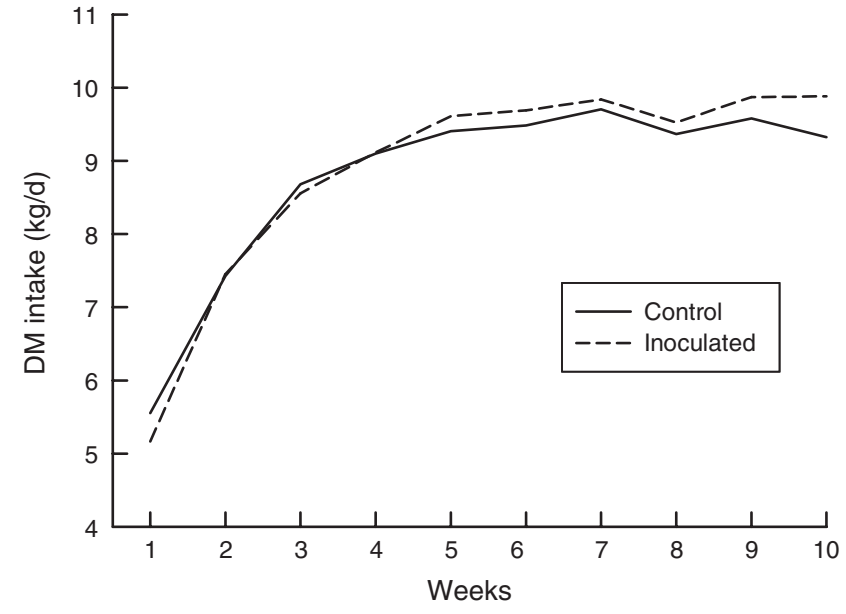

Fig. 1. Changes in dry matter intake by steers over the trial period (weekly averages).

removed from the experiment. One other control steer appeared lethargic at Week 5 but showed no signs of laminitis and was monitored but not removed.

Ruminal $\mathrm{pH}$ was not affected $(P>0.05)$ by inoculation at any recording time and remained relatively high $(\sim 6.8)$. Except for three control-group steers, lactic acid remained at trace levels

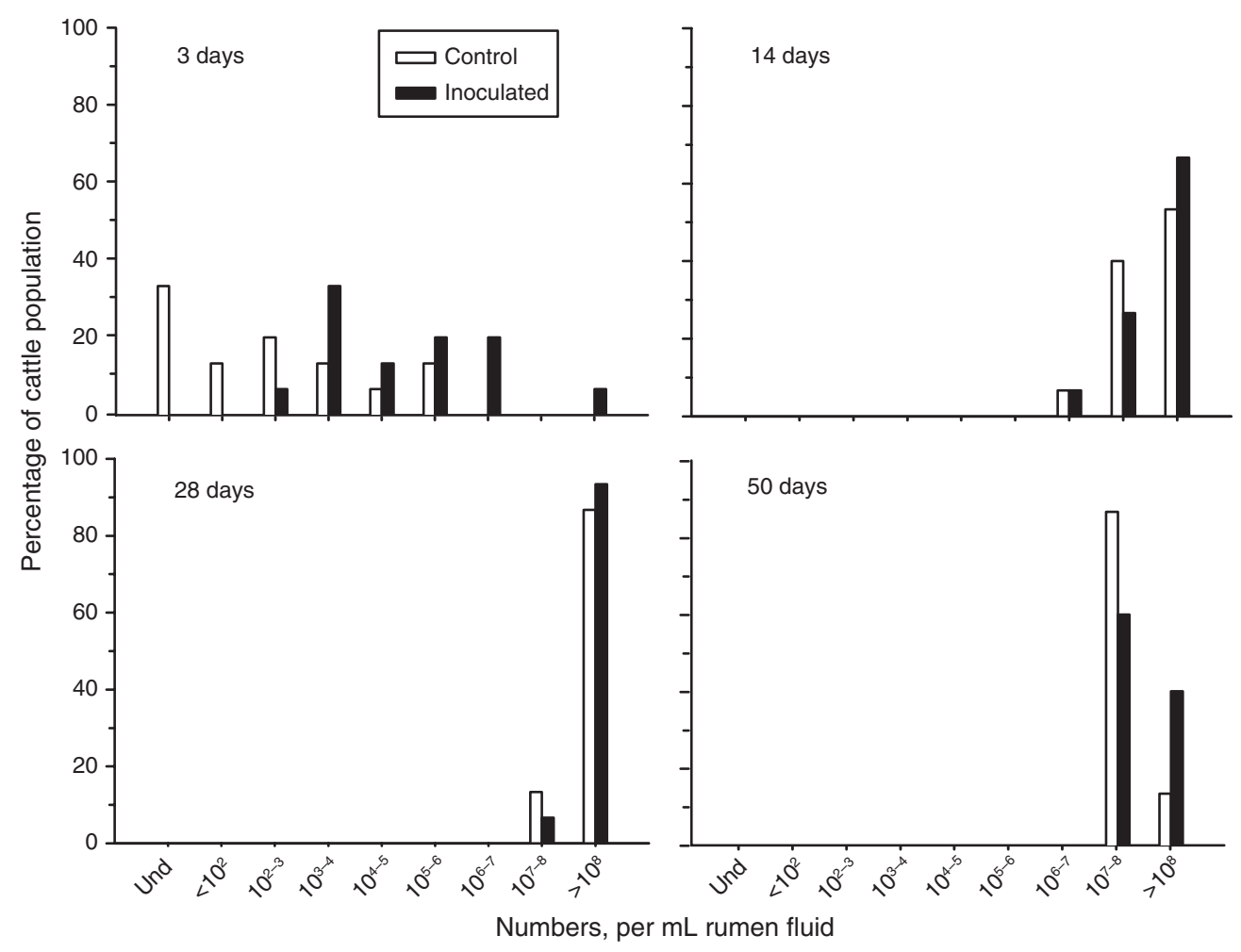

Fig. 2. Frequency of occurrence (percentage of cattle population) within the sampled cattle of Megasphaera elsdenii at given population densities. The scale is based on grouping on a logarithmic population density basis; e.g. $10^{5-6}$ represents a bacterial population density between $10^{5}$ and $10^{6}$ of M. elsdenii cell equivalents per $\mathrm{mL}$ of rumen fluid, where Und represents a population density below detectable limits. 
(below $1 \mathrm{mM}$ ). Even in these three steers, the maximum lactic acid concentration was $11.45 \mathrm{mM}$, well below the normal concentrations of $100 \mathrm{mM}$ or greater, generally associated with acidotic cattle (Klieve et al. 2003).

\section{Bacterial population changes}

Numbers of the inoculant bacteria, M. elsdenii and R. bromii, and also $S$. bovis, a lactic acid-producing bacterium often implicated in acute lactic acidosis (Mackie et al. 2002), in ruminal contents of the sampled cattle at Days 3, 14, 28 and 50 are presented in Figs $2-4$, respectively. Data are presented as frequency graphs, with the percentage of sampled animals in each treatment group with populations within each log-value range (e.g. numbers of bacteria between $10^{5}$ and $10^{6}$ per $\mathrm{mL}$ ) being plotted.

Populations of $M$. elsdenii were present in all inoculated steers generally at densities between $10^{3}$ and $10^{7}$ cells per $\mathrm{mL}$ by Day 3 (Fig. 2). By this day, M. elsdenii was also detected in $70 \%$ of the control steers, generally at a lower density but as high as $10^{6}$ per $\mathrm{mL}$. Megasphaera elsdenii populations rapidly increased in all steers of both groups, and by Day 14, were present at relatively high densities $\left(10^{7}-10^{8}\right.$ cells per $\mathrm{mL}$ of rumen fluid), where they appeared to stabilise for the remainder of the experiment.

Changes in $R$. bromii populations are presented in Fig. 3. At Day 3, R. bromii had established in all inoculated steers at densities between $10^{5}$ and $10^{9}$ cells per $\mathrm{mL}$, but numbers were below detection limits in all the control steers. By Day 14, the $R$. bromii population in inoculated steers had increased markedly, with numbers above $10^{9}$ cells per $\mathrm{mL}$ in $50 \%$ of steers. At the same time, the population density was increasing in the control steers, with a few steers $(20 \%)$ having high numbers $\left(10^{6}-10^{8}\right.$ cells per $\mathrm{mL}), 40 \%$ having $10^{4}-10^{5}$ cells per $\mathrm{mL}$ and $\sim 30 \%$ still having undetectable populations. By Day 28, populations had declined markedly in both groups of steers, with all the inoculated animals having populations of $<10^{5}$ cells per $\mathrm{mL}$, while $R$. bromii was not detectable in $55 \%$ of the control steers. At Day 50 , the $R$. bromii population had declined to undetectable levels in all but one control-group steer.

Streptococcus bovis populations (Fig. 4) were generally between $10^{6}$ and $10^{7}$ cells per $\mathrm{mL}$ throughout the entire trial. A few control steers had higher population densities at Day 3 (above $10^{8}$ cells per $\mathrm{mL}$ ) but these did not persist. As the trial progressed, the population density of $S$. bovis decreased in many of the sampled steers and even became undetectable in a few steers at 28 and 50 days into the trial.

\section{Identification of starch utilisers displacing R. bromii}

To determine what changes had occurred in the rumen ecosystem over the time period involved and whether the bacteria replacing $R$. bromii were always the same or not, DGGE gels were run on total DNA from ruminal contents from eight of the steers (six inoculated and two control) on Days 3, 14, 28 and 50. The steers selected were those in which $R$. bromii had initially established and then disappeared. Results for one representative steer are presented in Fig. 5. In this steer, R. bromii appeared dominant at

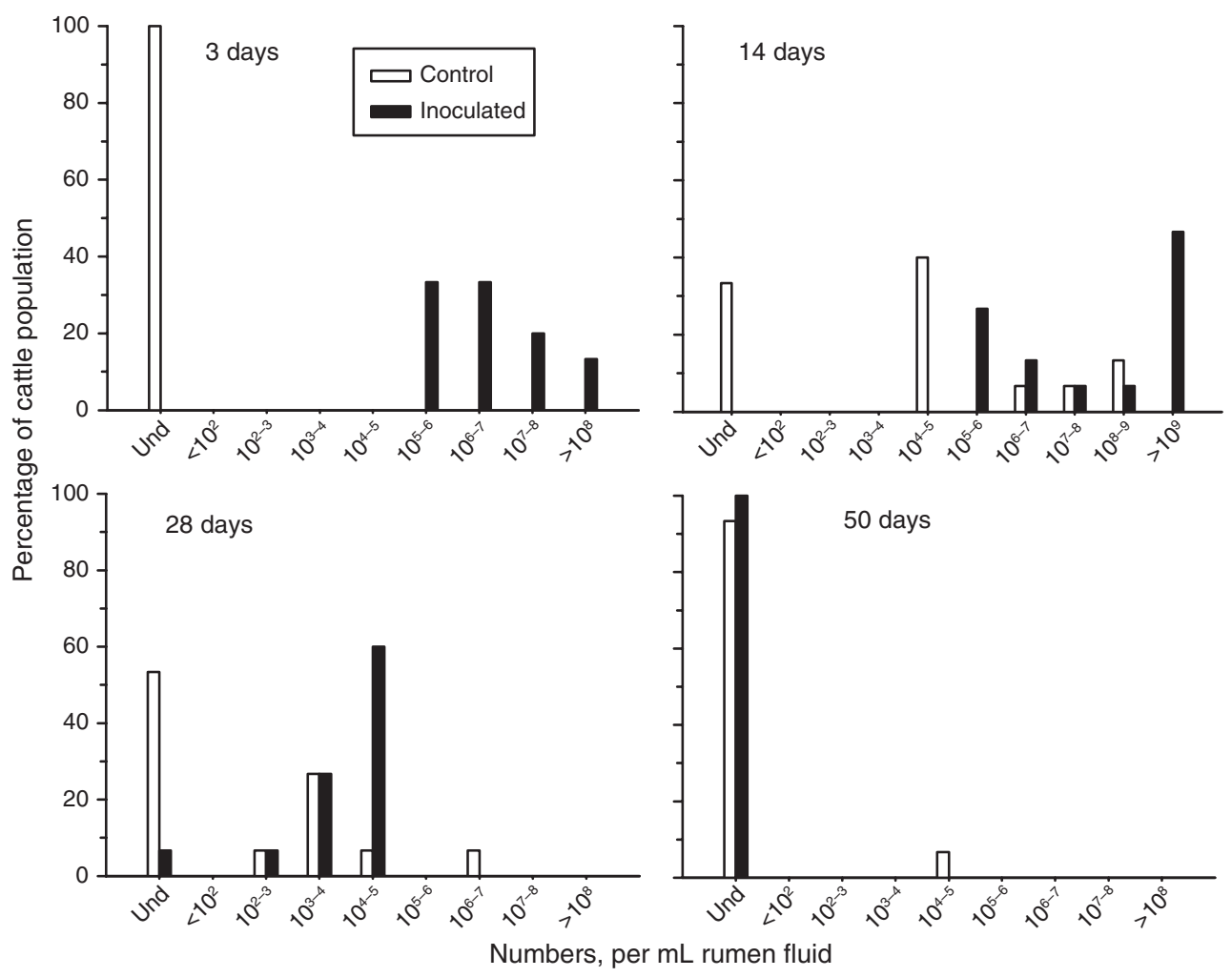

Fig. 3. Frequency of occurrence (percentage of cattle population) within the sampled cattle of Ruminococcus bromii at given population densities. The scale is based on grouping on a logarithmic population density basis; e.g. $10^{5-6}$ represents a bacterial population density between $10^{5}$ and $10^{6}$ of $R$. bromii cell equivalents per $\mathrm{mL}$ of rumen fluid, where Und represents a population density below detectable limits. 


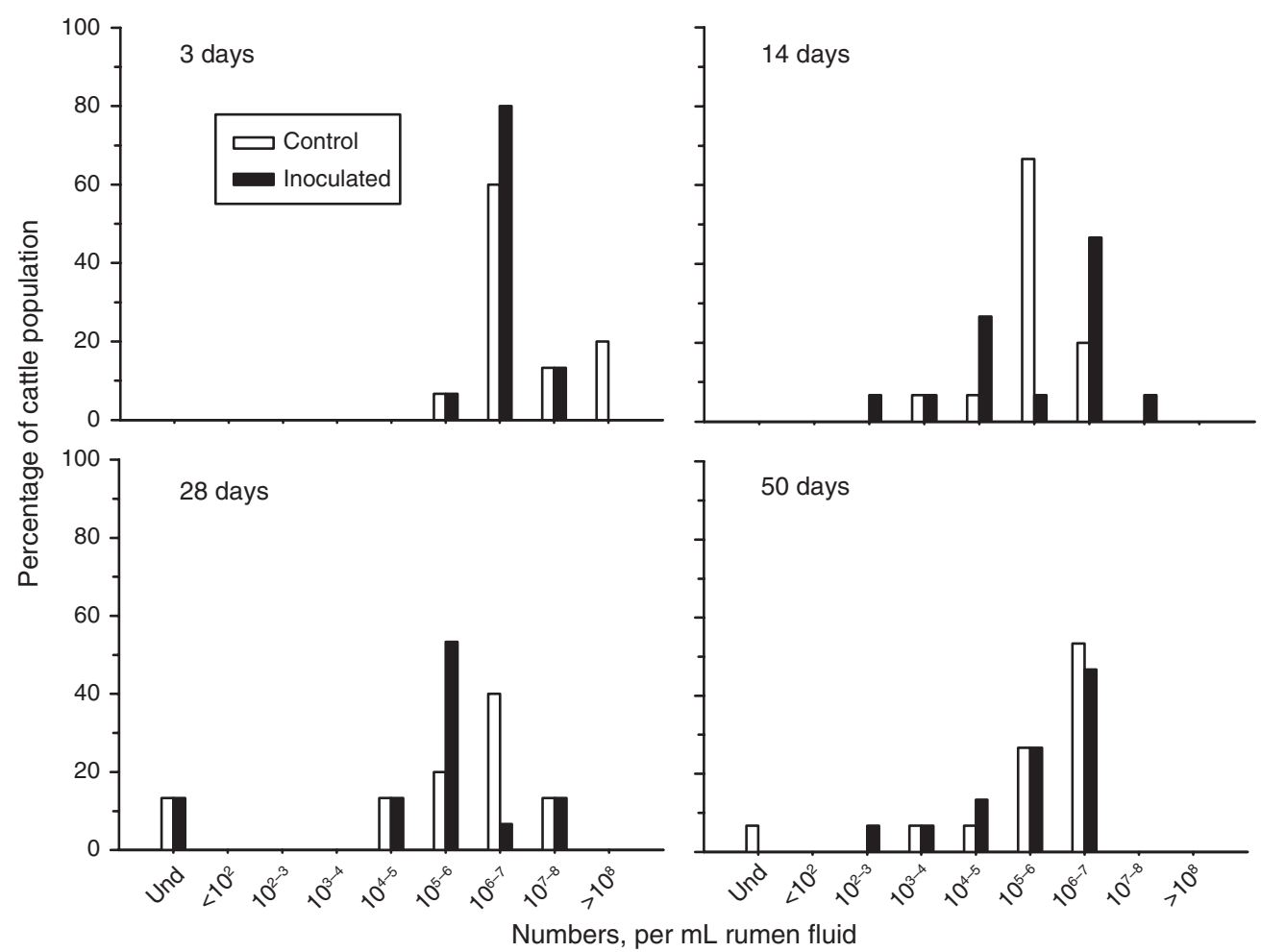

Fig. 4. Frequency of occurrence (percentage of cattle population) within the sampled cattle of Streptococcus bovis at given population densities. Scale is based on grouping on a logarithmic population density basis; for example, $10^{5-6}$ represents a bacterial population density between $10^{5}$ and $10^{6}$ of $S$. bovis cell equivalents per $\mathrm{mL}$ of rumen fluid, where Und represents a population density below detectable limits.

Day 14 but decreased in prominence after that, and two other bands, in particular, became very prominent and remained that way through to Day 50 . While $R$. bromii was not as evident in the DGGE profiles of all steers, the two very prominent bands that arose after Day 14 also dominated the banding profiles of the other steers examined (and in some were prominent from Day 14 onwards) and remained so. A comparison of DGGE patterns for the eight steers at Day 50 is presented in Fig. 6. This clearly shows the similarity in the bacterial population profiles of the steers by Day 50 and the prominence of these two bands (designated A and $\mathrm{B}$ ).

The sequences from Bands A and B were 96\% similar to each other over 193 base pairs. Band A shared 98\% similarity over 193 base pairs with the uncultured bacterial Clone 12-11, and Band B had $98 \%$ similarity over 193 base pairs with the uncultured bacterial Clone 12-18. In a study by Whitford et al. (1998), these clones originated from the rumen and branched with Ruminobacter amylophilus and the cluster had a bootstrap value of $100 \%$. However, Bands A and B had only $85 \%$ similarity to $R$. amylophilus ATCC 29744, which is sufficiently different from known culturable bacteria to be regarded as a novel species within a different genus [as defined by Bond et al. (1995)].

\section{Discussion}

High growth rates were achieved throughout the experiment in both the inoculated and control steers (Fig. 2), but particularly in the first 4 weeks, which could have resulted partly from some re-alimentation after transport and depasturing in unfamiliar paddocks before induction. Growth rates generally reflected changes in intake and were slightly higher for inoculated than control steers for the final 6 weeks, but poor performance of a few individual steers in the control group may have contributed to this. These differences were not significant.

It is unlikely that acidosis occurred in this experiment. Lactic acid concentrations and $\mathrm{pH}$ in rumen fluid of the steers tend to indicate that ruminal lactic acidosis was not affecting steers in this experiment, even though monensin was not included in the diet. Although $\mathrm{pH}$ and lactic acid concentrations were measured only once on the day of sampling, and then early in the morning before feeding when $\mathrm{pH}$ in particular would be expected to be at a high point (least acidic), no values for $\mathrm{pH}$ at any time fell below 5.5.

The general lack of differences in performance between the inoculated and control steers and the fact that all performed at expected levels for cattle in feedlots, may be due to the rapid acquisition of one of the inoculant bacteria in control-group cattle, and the transient dominance of the other. The acquisition of detectable populations of $M$. elsdenii in control steers was much more rapid than expected and more rapid than previously observed. Klieve et al. (2003) inoculated M. elsdenii directly into the rumen of steers and did not detect $M$. elsdenii in any uninoculated steers (all were sampled) for at least 5 days. It is possible that in the present study the control group had M. elsdenii naturally present at higher levels than previously observed, or 


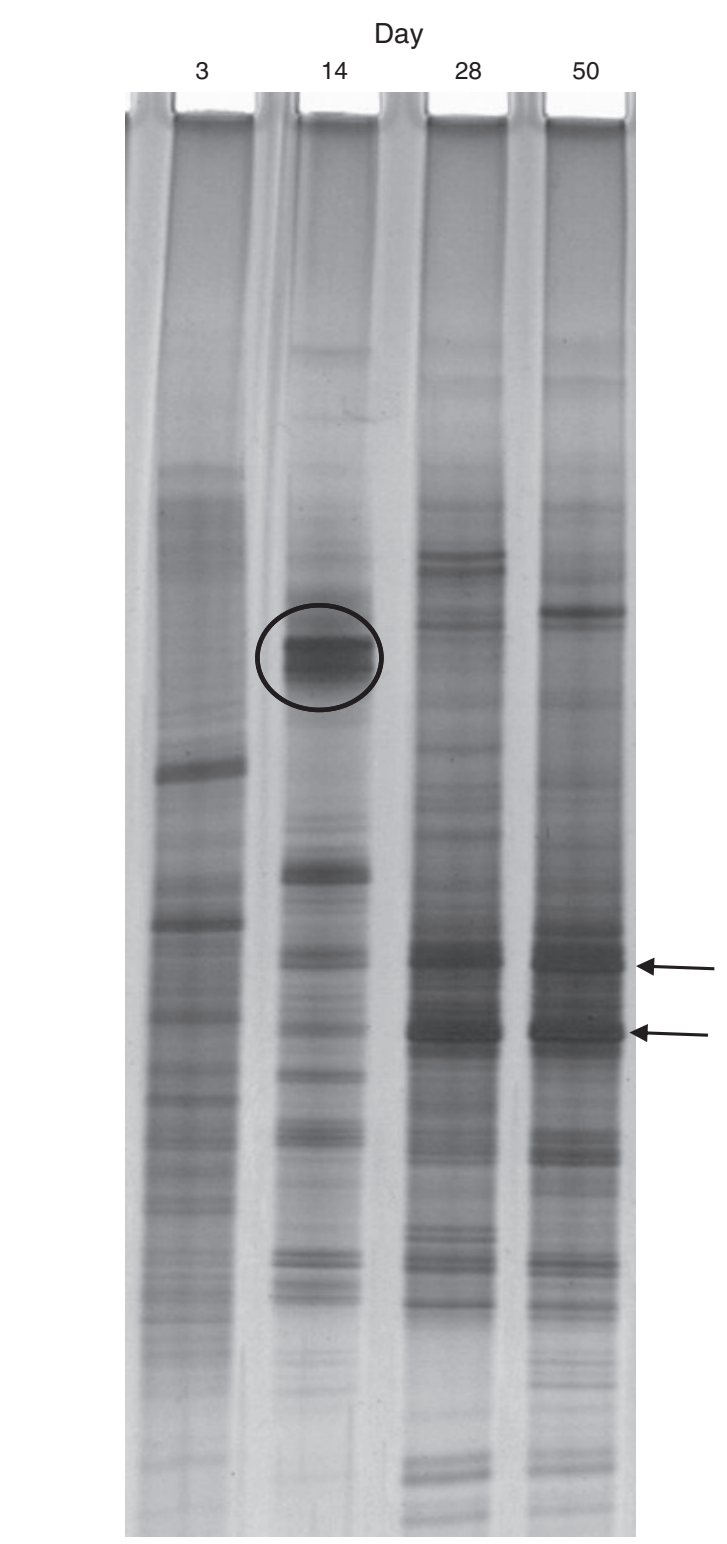

Fig. 5. Denaturing gradient gel electrophoresis profiles of bacterial diversity and abundance in the ruminal contents of steer 3620 (an inoculated group steer) on Days 3, 14, 28 and 50 post-inoculation. Banding typical of Ruminococcus bromii (Klieve et al. 2007) is circled and bands that became extremely prominent after Day 28 are arrowed.

M. elsdenii may have been acquired from the inoculated steers, despite considerable precautions being put in place to prevent this from happening. Determining the reason for the rapid acquisition of $M$. elsdenii by control-group steers will require further study but it also may question whether there is need to inoculate with $M$. elsdenii to achieve rapid population densities under all circumstances.

Ruminococcus bromii did not appear in the control steers until after Day 3, suggesting that it did not spread to, or was not able to colonise as quickly in uninoculated control steers, in the manner that $M$. elsdenii may have done. It appears that $R$. bromii is only transiently dominant during the early weeks of grain feeding and was not detected at any time in more than $30 \%$ of the control

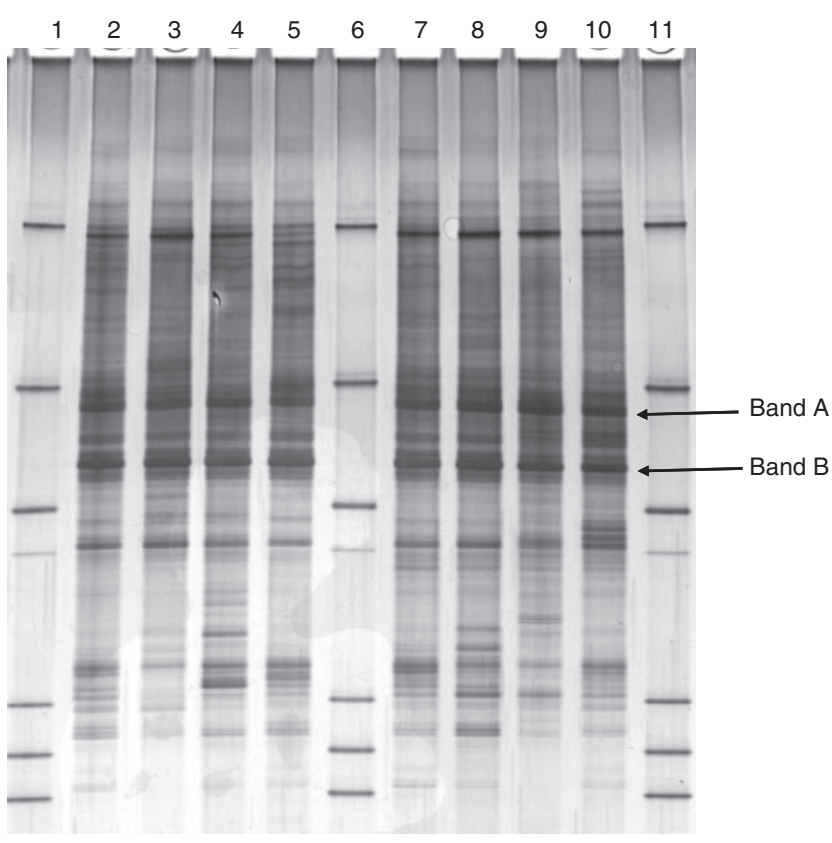

Fig. 6. Denaturing gradient gel electrophoresis profiles from the rumen contents of eight steers fed grain for 50 days. Lanes 1, 6 and 11 are reference markers. Bands arrowed had DNA excised, cloned and sequenced.

steers. Furthermore, the presence or absence of this bacterium does not appear to have had an influence on intake or liveweight gain of the steers. It was noted with hindsight that in previous work where $R$. bromii had been shown to be the dominant-starchutilising bacterium in barley-fed cattle (Klieve et al. 2007), these cattle had been on grain for 14 days, the time at which the $R$. bromii populations were maximal in the current work. The importance of the transient dominance of $R$. bromii in the development of an efficient and stable microbial ecosystem that is capable of utilising a high grain diet remains an open question. Previous work with Bos taurus steers (Klieve et al. 2007) indicated that at 14 days, $R$. bromii was a dominant component of the ruminal ecosystem in all of the cattle used (10 in total), which was a natural occurrence as none of these animals had been inoculated with this bacterial species. This contrasts with the low detection threshold ( $30 \%$ in control steers) of $R$. bromii in the current work.

Streptococcus bovis is often implicated in lactic acidosis (Nocek 1997) but recent work has suggested that the population density rarely increases unless the ruminal ecosystem is compromised (Mackie et al. 2002; Klieve et al. 2003). S. bovis populations were generally $10^{6}-10^{7}$ cells per $\mathrm{mL}$ of rumen fluid throughout the entire trial, which is in agreement with previous reports (Mackie et al. 2002; Klieve et al. 2003). A few control steers had higher populations at Day 3 (above $10^{8}$ cells per $\mathrm{mL}$ ) but these did not persist. As the trial progressed, the population density of $S$. bovis decreased in many of the sampled steers and became even undetectable in a few steers at 28 and 50 days into the trial.

Given the transience of $R$. bromii in the rumen of steers in our study, it was important to find out what bacterial species became dominant when $R$. bromii declined and whether they persisted in 
the ecosystem when the steers were using the grain-based diet efficiently. The rumen bacterial populations of eight steers were examined by DGGE and it was found that stable communities generally developed in the steers between 14 and 28 days on grain. The communities were very similar among all steers investigated, as indicated by the similarity of DGGE profiles across animals, with two bands in particular remaining prominent in all steers once the communities had stabilised. These bacteria appear to be related to the genus Ruminobacter but are likely to be novel species within a novel genus. However, further sequencing will be required to clarify the relationship to Ruminobacter, because the current sequencing data are based on a short (193 base pair) piece of DNA from the 16S rRNA gene and across a hypervariable region. In future, we will endeavour to isolate these bacteria because they may be important in the establishment of a stable bacterial community in cattle fed a grain-based (at least barley-based) diet.

It should also be considered that there may well be other, as yet unknown and uncultured, rumen bacteria that play a direct role in acidosis and it may be too simplistic to base the understanding of the overall process on the metabolic activity of a handful of culturable bacterial species.

In conclusion, in the present study, augmenting ruminal populations of $M$. elsdenii and $R$. bromii did not increase liveweight gain. However, in all the steers, the rate of liveweight gain was high and the incidence of acidosis negligible. The rapid acquisition of $M$. elsdenii in the present study could question the need to inoculate with the bacterium. The situation in terms of changes in dominant starch-utilising populations when animals are introduced to a grain diet appears more complex than initially thought, with $R$. bromii becoming transiently dominant after approximately 2 weeks on the diet. Numbers of this species then rapidly waned and bacteria related to Ruminobacter appeared in the ecosystem, and at apparently high density, although this will require future clarification. Whether it is important for $R$. bromii, or other species, to dominate in the ecosystem for short periods of time while the ecosystem is adapting to the dietary change, remains to be determined but could be an important step in the adaptation process.

\section{Acknowledgements}

We thank Megan Penny, Jim Kidd, Andrea Turner, Tim Grant and Ian Brock for technical assistance and David Reid for biometrical assistance. This work was co-funded by Meat and Livestock Australia through the Cooperative Research Centre for Cattle and Beef Quality.

\section{References}

Bond PL, Hugenholtz P, Keller J, Blackall LL (1995) Bacterial community structures of phosphate-removing and non-phosphate-removing activated sludges from sequencing batch reactors. Applied and Environmental Microbiology 61, 1910-1916.

Dawson KA, Allison MJ (1988) Digestive disorders and nutritional toxicity. In 'The rumen microbial ecosystem'. (Ed. PN Hobson) pp. 445-459. (Elsevier Science Publishers Ltd: London)

Dunlop RH (1972) Pathogenesis of ruminant lactic acidosis. Advances in Veterinary Science and Comparative Medicine 16, 259-302.
Godfrey SI, Rowe JB, Thorniley GR, Boyce MD, Speijers EJ (1995) Virginiamycin to protect sheep fed wheat, barley or oats from grain poisoning under simulated drought feeding conditions. Australian Journal of Agricultural Research 46, 393-401. doi:10.1071/AR9950393

Klieve AV, Holroyd RG, Turner AF, Lindsay JA (1998) Rumen bacterial and protozoal populations in cattle being relocated in tropical Queensland. Australian Journal of Agricultural Research 49, 1153-1159. doi:10.1071/A97164

Klieve AV, Ouwerkerk D, Turner A, Roberton R (2002) The production and storage of a fermentor-grown bacterial culture containing Synergistes jonesii, for protecting cattle against mimosine and 3-hydroxy-4 $(1 \mathrm{H})$ pyridone toxicity from feeding on Leucaena leucocephala. Australian Journal of Agricultural Research 53, 1-5. doi:10.1071/AR00121

Klieve AV, Hennessey D, Ouwerkerk D, Forster RJ, Mackie RI, Attwood GT (2003) Establishing populations of Megasphaera elsdenii YE 34 and Butyrivibrio fibrisolvens YE 44 in the rumen of cattle fed high grain diets. Journal of Applied Microbiology 95, 621-630. doi:10.1046/j.13652672.2003.02024.x

Klieve AV, O'Leary MN, McMillen L, Ouwerkerk D (2007) Ruminococcus bromii, identification and isolation as a dominant community member in the rumen of cattle fed a barley diet. Journal of Applied Microbiology 103, 2065-2073. doi:10.1111/j.1365-2672.2007.03492.x

Kocherginskaya SA, Cann IKO, Mackie RI (2005) Denaturing gradient gel electrophoresis. In 'Methods in gut microbial ecology for ruminants'. (Eds HPS Makkar, CS McSweeney) pp. 119-128. (International Atomic Energy Agency and Springer Academic Press: Dordrecht)

Kung LJ, Hession AO (1995) Preventing in vitro lactate accumulation in ruminal fermentations by inoculation with Megasphaera elsdenii.Journal of Animal Science 73, 250-256.

Lawrence RJ (1998) A comparison of feedlot bunk management strategies and their influence on cattle performance and health. Australian Society of Animal Production Proceedings 22, 177-180.

Mackie RI, McSweeney CS, Klieve AV (2002) Microbial ecology of the ovine rumen. In 'Sheep nutrition'. (Eds M Freer, H Dove) pp. 71-94. (CAB International, CSIRO Publishing: Melbourne)

Muyzer G, Waal ECd, Uitterlinden AG (1993) Profiling of complex microbial populations by denaturing gradient gel electrophoresis analysis of polymerase chain reaction-amplified genes coding for $16 \mathrm{~S}$ rRNA. Applied and Environmental Microbiology 59, 695-700.

Nocek JE (1997) Bovine acidosis: implications on laminitis. Journal of Dairy Science 80, 1005-1028. doi:10.3168/jds.S0022-0302(97)76026-0

Ouwerkerk D, Klieve AV (2001) Bacterial diversity within feedlot manure. Anaerobe 7, 59-66. doi:10.1006/anae.2001.0373

Ouwerkerk D, Klieve AV, Forster RJ (2002) Enumeration of Megasphaera elsdenii in rumen contents by real-time Taq nuclease assay. Journal of Applied Microbiology 92, 753-758. doi:10.1046/j.1365-2672.2002. 01580.x

Owens FN, Secrist DS, Hill WJ, Gill DR (1998) Acidosis in cattle: a review. Journal of Animal Science 76, 275-286.

Shu Q, Gill HS, Hennessey DW, Leng RA, Bird SH, Rowe JB (1999) Immunisation against lactic acidosis in cattle. Research in Veterinary Science 67, 65-71. doi:10.1053/rvsc.1998.0284

Strobel HJ, Russell JB (1986) Effect of pH and energy spilling on bacterial protein synthesis by carbohydrate-limited cultures of mixed rumen bacteria. Journal of Dairy Science 69, 2941-2947. doi:10.3168/jds. S0022-0302(86)80750-0

Teather RM (1982) Maintenance of laboratory strains of obligately anaerobic rumen bacteria. Applied and Environmental Microbiology 44, 499-501.

Whitford MF, Forster RJ, Beard CE, Gong J, Teather RM(1998) Phylogenetic analysis of rumen bacteria by comparative sequence analysis of cloned 16S rRNA genes. Anaerobe 4, 153-163. doi:10.1006/anae.1998.0155

Wiryawan KG, Brooker JD (1995) Probiotic control of lactate accumulation in acutely grain-fed sheep. Australian Journal of Agricultural Research 46, 1555-1568. doi:10.1071/AR9951555 